\title{
A Mössbauer Study of Solvation Effects of Five-Coordinated Iron(III) Complexes with Sulfur-Containing Ligands
}

\author{
By J. L. K. F. DE VRIES, J. M. TROOSTER, AND E. DE BOER*
}

Received December 17, 1969

Mössbauer spectra of bis( $N, N$-diethyldithiocarbamato)iron(III) chloride and thiocyanate and the tetrabutylammonium salts of bis(maleonitriledithiolato)iron(III) and bis(toluenedithiolato)iron(III) were measured. The observed large reduction of the quadrupole splitting on going from the solid state to the solution has been explained by a change from five- to six-coordination, brought about by the binding of a solvent molecule. Some four-line spectra observed for the solid state may be explained as superposition spectra of partly five- and partly six-coordinated iron.

\section{Introduction}

It is well known that iron(III) complexes with bidentate sulfur-containing ligands occur in the solid state as five-coordinated compounds. ${ }^{1-3}$ The structure of these compounds in solution, however, is unknown. In a recent review article ${ }^{4}$ it was suggested that six-coordination might occur in solution; the resulting complex will then contain one or two solvent molecules. Such a transformation should reveal itself in the Mössbauer spectra of these iron(III) compounds and we decided therefore to investigate the solvation effect by means of Mössbauer spectroscopy.

The spectra of $\operatorname{bis}(N, N$-diethyldithiocarbamato)iron(III) chloride and thiocyanate (Figure 1, I; dtc)

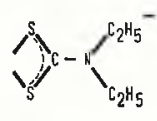

I

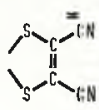

II

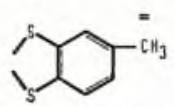

III

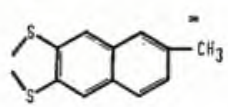

II
Figure 1.

and the tetrabutylammonium salts of bis(maleonitriledithiolato)iron(III) (Figure 1, II; MNT) and bis(toluenedithiolato)iron(III) (Figure 1, III; TDT) show indeed a considerable decrease in the quadrupole splitting (QS) when these compounds are dissolved. We believe that the transformation to six-coordination is responsible for this.

\section{Experimental Section}

a. Preparation.-The complexs were prepared as described elsewhere, ${ }^{5-7}$ the purity being checked by $\mathrm{C}, \mathrm{H}$, and $\mathrm{N}$ analyses; deviations from the theoretical contents did not exceed $0.4 \%$. The purity of the compounds under investigation was confirmed by the Mössbauer spectra, which are identical with published

* To whom correspondence should be addressed.

(1) B. F. Hoskins, R. I. Martin, and A. H. White, Nature (London), 211, 627 (1966).

(2) W. C. Hamilton and R. Spratley, Acla Crystallogr., Sect. A, 21, 142 (1966).

(3) A. Davison, N. Edelstein, R. H. Holm, and A. H. Maki, Inorg. Chem., 3,814 (1964).

(4) C. Furlani, Coord. Chem. Rev., 3, 141 (1968).

(5) H. H. Wickman and A. M. Trozzolo, Inorg. Chem., 7, 63 (1968).

(6) J. F. Weiher, L. R. Melby, and R. E. Benson, J. Amer. Chem. Soc., 86, 4329 (1964).

(7) R. Williams, E. Billig, J. H. Waters, and H. B. Gray, ibid., 88, 43 (1966). spectra. ${ }^{8-10}$ The ir and $\mathrm{uv}$-visible spectra of $\mathrm{Fe}(\mathrm{dtc})_{2} \mathrm{Cl}$ are also the same as published elsewhere. ${ }^{11}$

b. Mössbauer Measurements.-Mössbauer spectra were recorded on a constant-acceleration apparatus, ${ }^{67} \mathrm{Co}$ in palladium being used as a source. All spectra, listed in Table I, were recorded at liquid nitrogen temperature. The isomer shifts (IS) are given relative to sodium nitroprusside; the accuracy of the data is $0.04 \mathrm{~mm} / \mathrm{sec}$ for the solid compounds and the dimethylformamide (DMF) and pyridine solutions but $0.08 \mathrm{~mm} / \mathrm{sec}$ for the other solutions. In the latter case the accuracy is limited by the large line width and the small Mössbauer fraction of these dilute solutions. In nonpolar solvents like chloroform and benzene the absorption was insufficient to get reliable data; the best spectra were obtained in DMF, the solutions being about 0.03 M.

As $\mathrm{Fe}(\mathrm{dtc})_{2} \mathrm{Cl}$ in solution can be hydrolyzed ${ }^{11}$ or converted to the tris-dtc complex, ${ }^{6}$ all solutions were prepared shortly before the measurements. They were injected in a polypropylene capsule $^{12}$ filled with cotton, immediately sealed off, and cooled down to liquid nitrogen temperature. Spectra of samples not prepared under these conditions sometimes showed extra lines which were not reproducible and were therefore ascribed to decomposition products.

c. Other Physical Measurements.-Ir spectra were recorded on a Hitachi EPI-G3 in the $4000-700-\mathrm{cm}^{-1}$ region (KBr disks) and on a Hitachi EPI-L in the $700-200-\mathrm{cm}^{-1}$ region (CsI disks). Electronic spectra were taken with a Cary 14 spectrometer. In the 5000-12,000- $\mathrm{cm}^{-1}$ region the compounds were also measured in the solid state; as samples we used $\mathrm{KBr}$ disks containing about 15 $\mathrm{mg} / \mathrm{cm}^{2}$ of complex. The $\mathrm{C}, \mathrm{H}$, and $\mathrm{N}$ analyses were performed on a Perkin-Elmer 240 instrument. For conductivity measurements use was made of a Wayne Kerr B 641 universal bridge.

\section{Results and Discussion}

The results of our measurements are collected in Tables I and II. The most striking result is the reduction of the QS on going from the solid state (about 2.8 $\mathrm{mm} / \mathrm{sec}$ ) to the solution (about $0.7 \mathrm{~mm} / \mathrm{sec}$ ).

1. Bis $(N, N$-diethyldithiocarbamato)iron(III) Chloride. a. The Mössbauer Spectra.-The structure of $\mathrm{Fe}(\mathrm{dtc})_{2} \mathrm{Cl}$ in the solid state has been depicted in Figure 2A. It exists in monomeric form and is five-coordinated, the $\mathrm{Fe}-\mathrm{Cl}$ distance being almost the same as the $\mathrm{Fe}-\mathrm{S}$ distances. ${ }^{1}$ According to calculations of Ake and Harris Loew ${ }^{13}$ the unusually large electric field gradient

(8) L. M. Epstein and D. K. Straub, Inorg. Chem., 8, 560 (1969).

(9) T. Birchall, N. N. Greenwood, and J. A. McCleverty, Nature (London), 215, 625 (1967).

(10) T. Birchall and N. N. Greenwood, J. Chem. Soc. A, 286 (1969)

(11) R. L. Martin and A. H. White, Inorg. Chem., 6, 712 (1967).

(12) L. May and D. K. Snediker, Nucl. Instrum. Methods, 55 , 183 (1967).

(13) R. L. Ake and M. Harris Loew, J. Chem. Phys., 52, 1098 (1970). 
TABle I

Mössbauer Parameters (mM/sec) of Some Iron Complexes in Solid State and in Solution In DMF, Measured at Liguid NTTROGEN TEMPERATURE

\begin{tabular}{|c|c|c|c|c|}
\hline & \multicolumn{2}{|c|}{-Solid state } & \multicolumn{2}{|c|}{ Soln } \\
\hline & Is & QS & IS & QS \\
\hline $\mathrm{Fe}(\mathrm{dtc})_{2} \mathrm{Cl}$ & 0.70 & 2.76 & 0.70 & 0.70 \\
\hline $\mathrm{Fe}(\mathrm{dtc})_{2} \mathrm{SCN}$ & 0.68 & 2.65 & 0.68 & 0.79 \\
\hline $\mathrm{Fe}(\mathrm{dtc})_{3}$ & 0.70 & 0.52 & 0.69 & 0.66 \\
\hline $\mathrm{Fe}(\mathrm{MNT})_{2}-$ & 0.62 & 2.73 & 0.69 & 0.84 \\
\hline $\mathrm{Fe}(\mathrm{TDT})_{2}-$ & 0.59 & 3.09 & 0.68 & 0.85 \\
\hline
\end{tabular}

TABLE II

Mössbauer Parameters (Mm/Sec) of $\mathrm{Fe}$ (dtc) ${ }_{2} \mathrm{Cl}$ in Various -Solvents, Measured at Liguid Nitrogen Temperature

$\begin{array}{lcc} & \text { IS } & \text { QS } \\ \text { Dimethylformamide } & 0.70 & 0.70 \\ \text { Acetonitrile } & 0.72 & 0.77 \\ \text { Dimethyl sulfoxide } & 0.71 & 0.84 \\ \text { 1,2-Dimethoxyethane } & 0.73 & 0.85 \\ \text { Pyridine } & 0.70 & 0.71 \\ & 1.41 & 3.71 \\ \text { Thiocyanate in DMF } & 0.69 & 0.69 \\ & 1.40 & 2.38\end{array}$

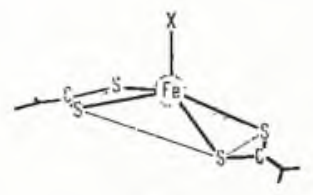

(A)

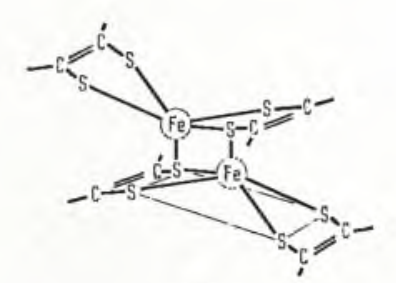

(B)
Figure 2.-Molecular structure diagrams of (A) $\operatorname{bis}\left(N, N^{-}\right.$ diethyldithiocerbamato)iron(III) and of (B) bis(maleonitriledithiolato)iron(III) iron. ${ }^{2,3}$

of this $\mathrm{Fe}$ (III) complex (see Table I) arises solely from the lattice. These authors assumed, however, that covalency effects could be entirely neglected. However, strong covalency is known to occur in dithiocarbamates of related metals, ${ }^{14,15}$ and a contribution to the electric field gradient from the valence electrons cannot be excluded. Recent calculations of the electric field gradient in some dithiolene complexes by Golding, $e t$ $a l .{ }^{16}$ support this. These authors explained the total field gradient by the valence electrons, taking into account covalency. ${ }^{16 \mathrm{a}}$

It is tempting to interpret the remarkable reduction of the QS on going from the solid state to the solution as a change in the coordination number from 5 to 6 caused by the binding of a solvent molecule, thus yielding a complex of higher symmetry. This change of geometry of the complex, resulting in a different order of the molecular orbitals involved is then responsible for the observed change in QS. This explanation is sup-

(14) R. Petterson and T. Vānngård, Ark. Kemi, 17, 249 (1960).

(15) H. van Willigen and J. G. M. van Rens, Chem. Phys. Lett., 2, 283 (1968).

(16) R. M. Golding, F, Jackson, and E. Sinn, Theor. Chim. Acta, 15, 123 (1969).

(16a) Note Added in Proof.-In cooperation with Dr. C. P. Keijzers we recently carried out extended Hückel calculations for $\mathrm{Fe}(d \mathrm{dc})_{2} \mathrm{Cl}$, by which method the occupation numbers of the iron $3 d$ and $4 p$ orbitals are obtained. Using these values the $Q S$ was calculated in good agreement obtained. Using these values the $Q S$ was calculated in good agreement
with the experimental values. This supports the statement that the lattice contribution to the electric freld gradient in $\mathrm{Fe}$ (dtc) ${ }_{2} \mathrm{Cl}$ is neslipible ported by the experimental data obtained for $\mathrm{Fe}(\mathrm{dtc})_{3}$, in which compound the iron atom is six-coordinated and located at the center of a distorted octahedron. ${ }^{17}$ This six-coordinated complex is like $\mathrm{Fe}(\mathrm{dtc})_{2} \mathrm{Cl}^{11}$ present in the monomeric form, both in the solid state and in solution. ${ }^{17}$ In chloroform solution about the same magnetic susceptibility has been measured for both compounds. ${ }^{11,17}$

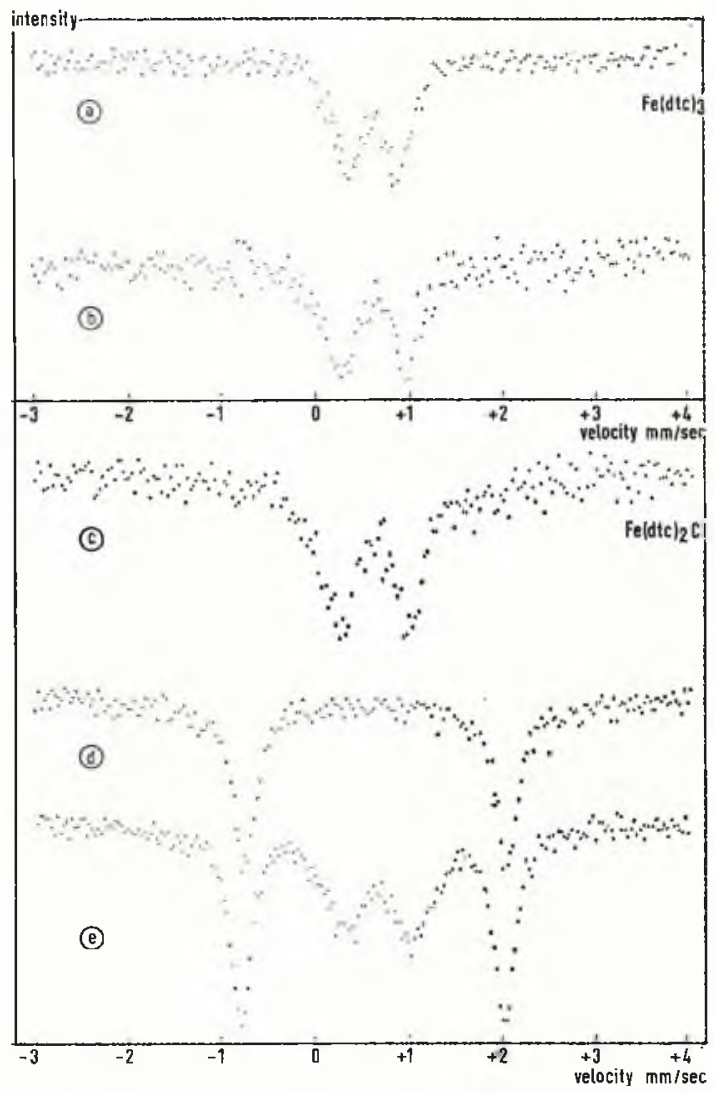

Figure 3.-Mössbauer spectra of $\mathrm{Fe}(\mathrm{dtc})_{3}$ (a) in solid state and (b) in DMF solution and of $\mathrm{Fe}(\mathrm{dtc})_{2} \mathrm{Cl}$ (c) in DMF solution, (d) in solid state, and (e) after complete removal of the DMF from sample (c). All spectra were recorded at liquid nitrogen temperature.

Figure 3 shows that the Mössbauer spectrum of $\mathrm{Fe}(\mathrm{dtc})_{2} \mathrm{Cl}$ in solution is almost identical with the spectrum of the six-coordinated $\mathrm{Fe}(\mathrm{dtc})_{3}$ in solution. The similarity in magnetic susceptibility and in the IS and QS parameters ( $c f$. Table I) suggests a geometrical correspondence between both complexes in solution, which can be attained by the binding of a solvent molecule to the sixth coordination site of the $\mathrm{Fe}(\mathrm{dtc})_{2} \mathrm{Cl}$ monomer. In principle, the solvent molecule may enter the complex either cis or trans with respect to the chlorine atom. The tables show that the Mössbauer parameters are not very sensitive to the type and position of the ligands in the complex. Therefore on the basis of the Mössbauer spectra alone we cannot decide which configuration is formed. However, chemical evidence favors the cis mode!.

It is Knowr? that Fe(dite) Cl can be rapidly and re-

(17) A. H. White, R, Reper, E. Kokot, II. Waverman, and R, L, Martin, 
versibly converted to $\mathrm{Fe}(\mathrm{dtc})_{3}{ }^{5,18}$ This can easily be understood for the cis configuration, since the iron atom has two neighboring sites available for binding the bidentate ligand. Therefore we favor a cis configuration for the $\mathrm{Fe}(\mathrm{dtc})_{2}(\mathrm{Cl})$ (solv) complex as depicted in Figure 4.

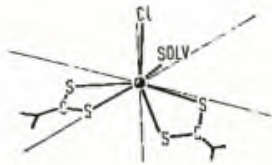

Figure 4.-Proposed model of the six-coordinated complex formed after dissolving $\mathrm{Fe}(\mathrm{dtc})_{2} \mathrm{Cl}$.

Tables I and II show that the IS does not vary markedly upon a change of coordination number or ligand. This has been observed previously: the IS's of $\mathrm{Fe}(\mathrm{MNT})_{3}{ }^{3-}$ and $\mathrm{Fe}(\mathrm{MNT})_{2}{ }_{2}$ differ by only $0.06 \mathrm{~mm} /$ sec, whereas $\mathrm{Fe}(\mathrm{MNT})_{2}{ }^{-}$and $\mathrm{Fe}(\mathrm{MNT})_{2}(\mathrm{py})-$ have the same IS. ${ }^{10}$ Also no change of IS is observed in the series $\mathrm{Fe}(\mathrm{dtc})_{2} \mathrm{X}, \mathrm{X}$ being $\mathrm{Cl}, \mathrm{Br}, \mathrm{I}, \mathrm{NCS}$, or $\mathrm{C}_{6} \mathrm{~F}_{6} \mathrm{CO}_{2}{ }^{8}$

As can be seen in Table II, a second site was observed for solutions of $\mathrm{Fe}(\mathrm{dtc})_{2} \mathrm{Cl}$ in pyridine and in DMF to which potassium thiocyanate was added. The large IS suggests that the extra lines belong to a high-spin iron(II) complex of which no further identification has been attempted.

b. The Electronic Spectra.-The proposed change of the coordination number must also reveal itself in a change of the $d-d$ transitions in the electronic spectrum. For that purpose we measured the electronic spectrum of $\mathrm{Fe}(\mathrm{dtc})_{2} \mathrm{Cl}$, both in solid form and in solution, in the region from 5000 to $12,000 \mathrm{~cm}^{-1}$. Figure 5 shows the

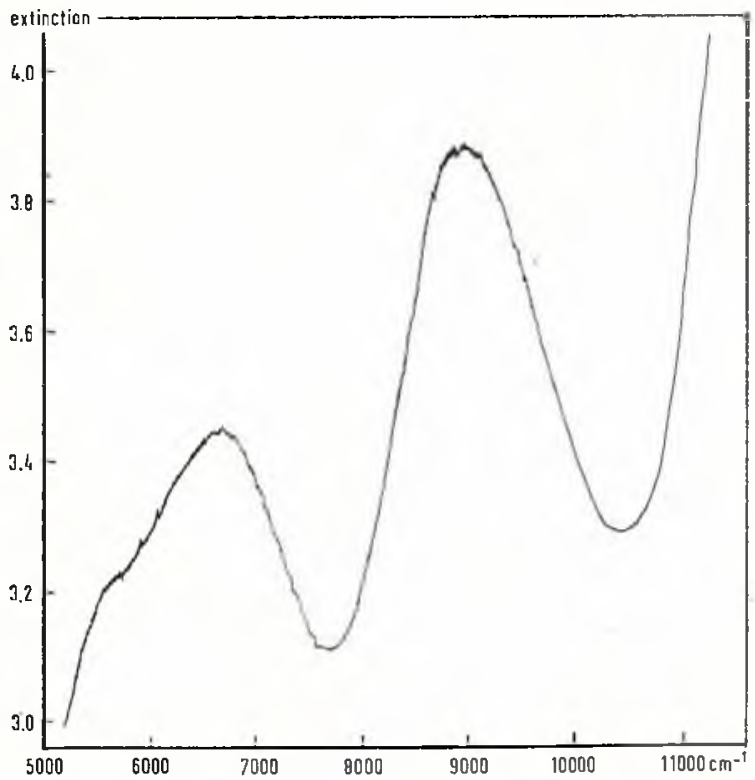

Figure 5.-Electronic spectrum of $\mathrm{Fe}(\mathrm{dtc})_{2} \mathrm{Cl}$, measured in a $\mathrm{KBr}$ disk.

spectrum of solid $\mathrm{Fe}(\mathrm{dtc})_{2} \mathrm{Cl}$; two distinct absorption bands are observed at 6300 and $8610 \mathrm{~cm}^{-1}$ and the presence of a third one can be discerned at about 5200 $\mathrm{cm}^{-1}$ as a shoulder on the band at $6300 \mathrm{~cm}^{-1}$. [A

(18) E. Frank and C. R. Abeledo, Inorg. Chem., 5, 1453 (1966). similar spectrum was obtained by Martin and White, ${ }^{11}$ by dissolving $\mathrm{Fe}(\mathrm{dtc})_{2} \mathrm{Cl}$ in the very weakly coordinating solvent $\mathrm{CCl}_{4}$. In other solvents with better coordinating power no spectrum was observed. One may conclude from this that $\mathrm{CCl}_{4}$ is not capable of coordinating with $\mathrm{Fe}(\mathrm{dtc})_{2} \mathrm{Cl}$. Unfortunately we could not verify this statement from the Mössbauer spectrum of $\mathrm{Fe}$ $(\mathrm{dtc})_{2} \mathrm{Cl}$ in $\mathrm{CCl}_{4}$, due to the low solubility and the small Mössbauer fraction.] In solution no absorption bands are observed in the $5000-12,000-\mathrm{cm}^{-1}$ region, even for saturated solutions and very long cells. The absorption spectrum outside this region (visible and uv) is the same as published spectra in the literature. ${ }^{11}$ It should also be noted that the same visible-uv spectrum is produced by the material having the small QS of 0.70 $\mathrm{mm} / \mathrm{sec}$.

The absence of absorption bands for solutions of $\mathrm{Fe}(\mathrm{dtc})_{2} \mathrm{Cl}$ in the optical region, where $\mathrm{d}-\mathrm{d}$ transitions for five-coordinated iron(III) complexes occur, strongly supports our conclusion that a change in coordination number takes place on dissolving $\mathrm{Fe}(\mathrm{dtc})_{2} \mathrm{Cl}$.

c. The Ir Spectra.-The presence of bound solvent molecules must also reveal itself in the ir spectra of the solutions. Unfortunately the solubility of $\mathrm{Fe}(\mathrm{dtc})_{2} \mathrm{Cl}$ in various solvents was not high enough to measure ir spectra. However, evidence for solvent binding was found by measuring ir spectra of the solid material, obtained by evaporating a $\mathrm{Fe}(\mathrm{dtc})_{2} \mathrm{Cl}$ solution in $\mathrm{DMF}$, which is a strongly coordinating solvent. In Figure 6

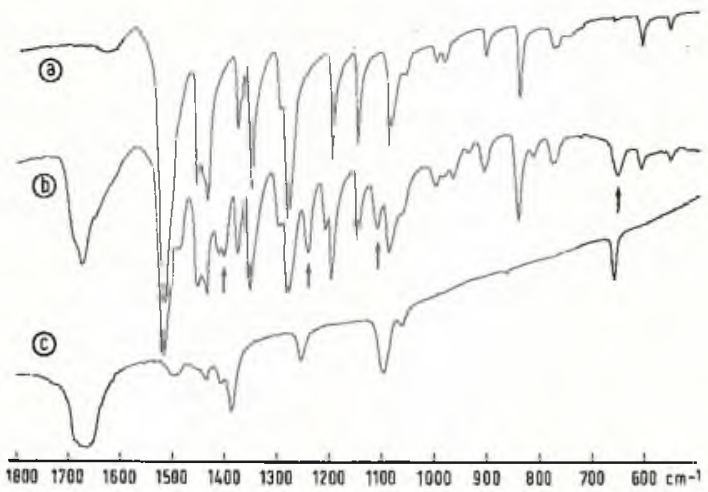

Figure 6.-Ir spectra of (a) pure $\mathrm{Fe}(\mathrm{dtc})_{2} \mathrm{Cl}$, (b) the solid after evaporating a DMF solution of $\mathrm{Fe}(\mathrm{dtc})_{2} \mathrm{Cl}$, and (c) pure DMF; all spectra have been measured in a $\mathrm{KBr}$ disk.

some relevant ir spectra are shown. The ir spectrum of the material, obtained from the solution, clearly shows peaks due to DMF. They are shifted with respect to corresponding positions in pure DMF. For example, in the complex peaks are found at 655,1110 , 1242 , and $1405 \mathrm{~cm}^{-1}$ (indicated by arrows in Figure 6), while in pure DMF these peaks are at 660, 1097, 1254, and $1388 \mathrm{~cm}^{-1}$. The Mössbauer spectra of these samples all contained the small QS of $0.70 \mathrm{~mm} / \mathrm{sec}$ thought to be indicative of six-coordination.

Removal of a weakly coordinating solvent like acetonitrile or chloroform resulted in unchanged $\mathrm{Fe}(\mathrm{dtc})_{2} \mathrm{Cl}$, as could be concluded from its ir and Mössbauer spectra. Hence no decomposition takes place by dissolving the compound. 
d. Reactions in DMF.- Some interesting phenomena occurring in DMF but not observed in other solvents merit special attention.

After evaporating to dryness a $\mathrm{Fe}(\mathrm{dtc})_{2} \mathrm{Cl}$ solution in $D M F$, the remaining bound solvent molectles could be completely removed by slightly heating the residue on the vacuum line. The ir spectrum of the residue resembled very much that of $\mathrm{Fe}(\mathrm{dtc})_{2} \mathrm{Cl}$ and no peaks due to DMF were present any more. The Mössbauer spectrum, however, surprisingly shows a four-line spectrum (see Figure 3e). It appeared to be a superposition of the spectrum of $\mathrm{Fe}(\mathrm{dtc})_{2} \mathrm{Cl}$ in the solid state and in solution. Thorough $\mathrm{C}, \mathrm{H}$, and $\mathrm{N}$ analyses of these samples proved that we are dealing with a compound having the same composition as the pure starting material. Anal. Calcd: C, 30.97; H, 5.20; N, 7.22. Found: C, 30.31, 30.47, 30.31, 30.29; H, 5.08, 5.23, $5.14,5.15 ; \mathrm{N}, 7.17,7.30,7.34,7.30$. Recrystallization of these samples from chloroform yielded the original complex, as indicated by its Mössbauer and ir spectra.

The observations can be rationalized, if dimer formation is assumed according to

$$
2 \mathrm{Fe}(\mathrm{dtc})_{2}(\mathrm{Cl})(\mathrm{DMF}) \rightleftharpoons\left[\mathrm{Fe}(\mathrm{dtc})_{2} \mathrm{Cl}\right]_{2}+2 \mathrm{DMF}
$$

Apparently the DMF coordinates so strongly that in the paste, formed by evaporation of DMF, the complex is able to retain six-coordination by forming dimers. The six-coordinated iron atom in the dimer will give a Mössbauer spectrum similar to the solvated $\mathrm{Fe}(\mathrm{dtc})_{2} \mathrm{Cl}$ in solution.

Another interesting observation was made when a DMF solution of $\mathrm{Fe}(\mathrm{dtc})_{2} \mathrm{Cl}$ was very slowly evaporated on a vacuum line. At the beginning of the evaporation process black crystals were formed, the ir spectrum being given in Figure 7, together with the ir spectrum of

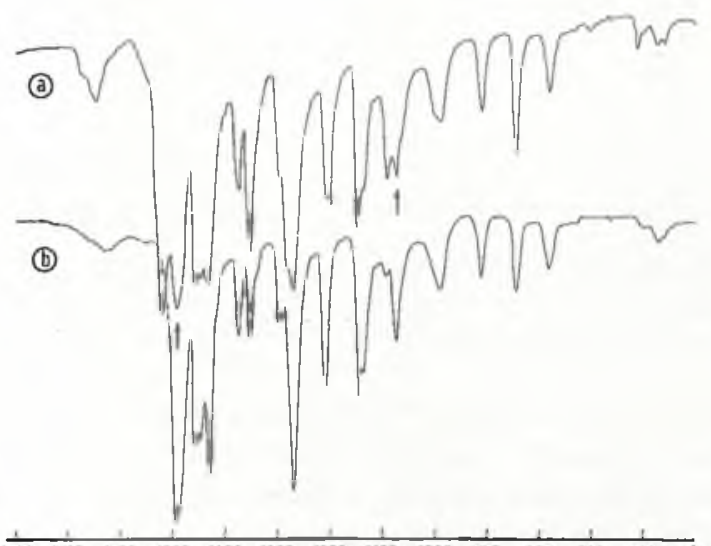

Figure 7.-Ir spectra of (a) crystals formed at slow evaporation of a $\mathrm{Fe}(\mathrm{dtc})_{2} \mathrm{Cl}$ solution in $\mathrm{DMF}$ and (b) pure $\mathrm{Fe}(\mathrm{dtc})_{3}$; both were measured in $\mathrm{KBr}$.

pure $\mathrm{Fe}(\mathrm{dtc})_{2}$. On close inspection it can be noticed that this spectrum is a superposition of the ir spectra of pure $\mathrm{Fe}(\mathrm{dtc})_{3}$ and $\mathrm{Fe}(\mathrm{dtc})_{2} \mathrm{Cl}$. This can be most clearly seen in those regions where the ir spectra of the two latter compounds differ markedly (in Figure 7 indicated by arrows). We conclude, therefore, that slow evaporation yields crystals which contain a fair amount of $\mathrm{Fe}(\mathrm{dtc})_{3}$. This conclusion is further supported by the Mössbauer spectrum of these crystals (a four-line spectrum due to $\mathrm{Fe}(\mathrm{dtc})_{2} \mathrm{Cl}$ and $\left.\mathrm{Fe}(\mathrm{dtc})_{3}\right)$ and the $\mathrm{C}$, $\mathrm{H}$, and $\mathrm{N}$ analyses.

e. Dissociation.-Slow addition of DMF to a solution of $\mathrm{Fe}(\mathrm{dtc}){ }_{2} \mathrm{Cl}$ in acetonitrile causes a 10 -fold increase in the conductivity. It was shown earlier ${ }^{11}$ that $\mathrm{Fe}(\mathrm{dtc})_{2} \mathrm{Cl}$ is a weak electrolyte and a dissociation in $\mathrm{Fe}(\mathrm{dtc})_{2}{ }^{+}$and $\mathrm{Cl}^{-}$ions was suggested. We prefer to formulate the dissociation process, in accord with our proposed model

$$
\mathrm{Fe}(\mathrm{dtc})_{2}(\mathrm{Cl})(\mathrm{solv})+\mathrm{solv} \rightleftharpoons \mathrm{Fe}(\mathrm{dtc})_{2}(\mathrm{solv})_{2}{ }^{+}+\mathrm{Cl}^{-}
$$

in which a chlorine atom is replaced by a solvent molecule, thus producing a disolvated Fe complex. The Mössbauer spectra of these solutions were indistinguishable from the other solution spectra.

In conclusion, the various reactions occurring in DMF can be exemplified by the reaction scheme

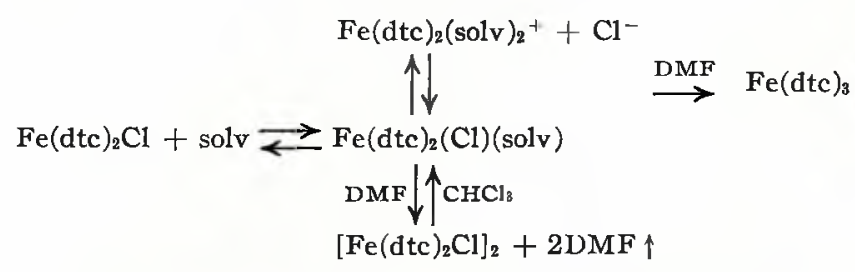

2. Dithiolene Complexes. - The five-coordination in the dithiolene complexes occurs in the solid state by association to dimers (Figure $2 \mathrm{~B}$ ) $;^{2,3}$ in the solvents which we used, $\mathrm{Fe}(\mathrm{MNT})_{2}-$ and $\mathrm{Fe}(\mathrm{MNT})_{2}-$ complexes are monomeric. ${ }^{19}$ In the solid state these compounds have a doublet spin state, whereas the monomers in solution have a quartet spin state. ${ }^{20}$ The reduction of the QS (see Table I and Figure 8) on dissolving these

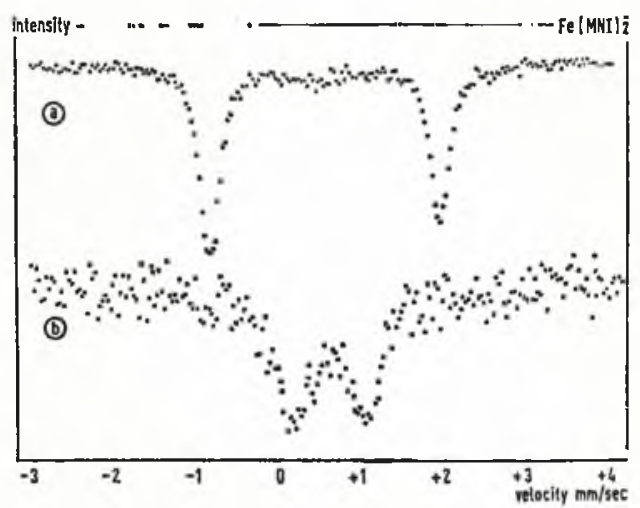

Figure 8.-Mössbauer spectra of $\mathrm{Fe}(\mathrm{MNT})_{2}{ }^{-}$(a) in solid state and (b) in DMF solution, at liquid nitrogen temperature.

complexes is similar to the effect observed for the dithiocarbamate complex, suggesting that also for these compounds six-coordination takes place in solution.

A comparison with the Mössbauer data of the complexes $\mathrm{Fe}(\mathrm{MNT})_{3^{3-}}$ and $\mathrm{Fe}(\mathrm{MNT})_{3}{ }^{2-}$, which in solid state have a $Q S$ of 1.69 and $1.57 \mathrm{~mm} / \mathrm{sec}$, respectively, ${ }^{10}$ cannot be made because these two complexes have one and two unpaired electrons, respectively.

(19) A. L. Balch, I. G. Dance, and R. H. Holn, J. Amer. Chem. Soc., 90, 1139 (1968).

(20) L. Carlin, Transition Metal Chem., 1, 263 (1965). 
On the analogy of the dithiocarbamate complexes we assume that a cis configuration is favored in the Fe$(\mathrm{MNT})_{2}(\text { solv })_{2}{ }^{-}$and $\mathrm{Fe}(\mathrm{TDT})_{2}(\text { solv })_{2}{ }^{-}$complexes. On heating in air, a $\mathrm{Fe}(\mathrm{MNT})_{2}-$ solution in acetone readily produces ${ }^{21} \mathrm{Fe}(\mathrm{MNT})_{3}{ }^{2-}$. When a solution of $\mathrm{Fe}(\mathrm{MNT})_{2}{ }^{-}$or of $\mathrm{Fe}(\mathrm{TDT})_{2}{ }^{-}$in DMF or in other solvents is evaporated on the vacuum line, the original Mössbauer spectrum is found again.

It is noteworthy that Stukan, et al.,22 in studying the related bis(naphthadithiolato)iron(III) complex (Figure 1, IV), found four-line Mössbauer spectra. The authors discussed the possibility of the simultaneous occurrence of a cis- and trans-solvated complex. According to our view such complexes will not have strongly different

(21) M. Gerloch, S. F. A. Kettle, J. Locke, and J. A. McCleverty, Chem. Commun., 2, 29 (1966).

(22) R. A. Stukan, V. I. Goldanskii, E. F. Makarov, and E. G. Ruchadse, Zh. Strukt. Khim., 8, 239 (1967).
Mössbauer spectra; therefore we propose an explanation similar to the one presented for $\mathrm{Fe}(\mathrm{dtc})_{2} \mathrm{Cl}$ : the spectrum consists of one site with five-coordination $\left[\mathrm{IS}=0.47, \mathrm{QS}=3.0 \mathrm{~mm} / \mathrm{sec} ; c f . \mathrm{Fe}(\mathrm{TDT})_{2}-\right.$ (solid state) IS $=0.59, Q S=3.09 \mathrm{~mm} / \mathrm{sec}]$ and one site with six-coordinated iron [IS $=0.58, Q S=0.82 \mathrm{~mm} / \mathrm{sec}$; cf. $\mathrm{Fe}(\mathrm{TDT})_{2}{ }^{-}$(in solution) IS $=0.68, \mathrm{QS}=0.85 \mathrm{~mm} /$ $\mathrm{sec}]$.

Acknowledgment.-We wish to thank Dr. H. van Willigen for helpful discussions and Miss M. Koning for her assistance in the experimental part of the work. We are grateful to Mr. J. Diersmann for carrying out the $\mathrm{C}, \mathrm{H}$, and $\mathrm{N}$ analyses. The work has been carried out under the auspices of the Netherlands Foundation for Chemical Research (SON) and with the aid of the Netherlands Organization for the Advancement of Pure Research (ZWO). 